\title{
Research on Wetting-Drying Cycles' Effect on the Physical and Mechanical Properties of Expansive Soil Improved by OTAC-KCl
}

\author{
Bao-tian Wang, ${ }^{1,2}$ Can-hong Zhang, ${ }^{1,2}$ Xue-lian Qiu, ${ }^{3}$ En-yue Ji, ${ }^{1,2}$ and Wen-hui Zhang ${ }^{1,2}$ \\ ${ }^{1}$ Key Laboratory of Ministry of Education for Geotechnics and Embankment Engineering, Hohai University, Nanjing, \\ Jiangsu 210098, China \\ ${ }^{2}$ Institute of Geotechnical Engineering, Hohai University, Nanjing, Jiangsu 210098, China \\ ${ }^{3}$ China Coal Technology and Engineering Group, Nanjing Design and Research Institute Co. Ltd., Nanjing, Jiangsu 210031, China
}

Correspondence should be addressed to Can-hong Zhang; 2008zhangcanhong@163.com

Received 21 August 2014; Revised 7 November 2014; Accepted 15 November 2014

Academic Editor: Guocheng Lv

Copyright (C) 2015 Bao-tian Wang et al. This is an open access article distributed under the Creative Commons Attribution License, which permits unrestricted use, distribution, and reproduction in any medium, provided the original work is properly cited.

Expansive soil experiences periodic swelling and shrinkage during the alternate wet and dry environments, which will result in severe damage to the slope stability. In this study, a promising modifier OTAC-KCl is introduced, which has a good diffusivity and is soluble in water or other solvents easily. Firstly, a reasonable combination of ameliorant $0.3 \% \mathrm{STAC}$ and $3 \% \mathrm{KCl}$ is chosen referring to the free swell test. Then, the best curing period, 14 days, is gotten from UCS tests. The effect of wetting and drying cycles on engineering properties of expansive soil improved by OTAC- $\mathrm{KCl}$ admixtures after 14-day curing is also studied accordingly. Both treated and untreated expansive soil samples are prepared for the cyclic wetting-drying tests which mainly include cyclic swelling potential and cyclic strength tests. Experimental results show that the swelling potential of expansive soil samples stabilized with OTAC- $\mathrm{KCl}$ is suppressed efficiently, and the untreated soil specimens will collapse when immersed in water while the treated specimens keep in good conditions. Moreover, expansive soil samples modified with $0.3 \%$ OTAC $+3 \% \mathrm{KCl}$ show enough durability on the swelling ability, shear strength, and unconfined compressive strength, which means, that both the physical and the mechanical properties of stabilized expansive soil have been improved effectively.

\section{Introduction}

Expansive soil is a kind of high plasticity clay which has obvious swell-shrink characteristics. It also has the engineering properties of shrinking and cracking due to water loss and the swelling and softening due to the moisture content increase $[1,2]$. Expansive soil problem mainly comes from its water stability.

Recently, numerous researchers have investigated the influence of wetting-drying cycles on the engineering properties of natural clay [3,4]. The work of Ring [5] indicated that the specimens' height during 4 wetting and drying cycles is the same and the initial compaction conditions are even independent. Popescu [6], Osipov et al. [7], and Basma et al. [8] studied expansive soil basic properties with full shrinkage method and found that the swelling ability of specimens increases with the number of wetting and drying cycles. Such cyclic swelling and shrinkage potentials of the ground will cause severe damage to the overlying structures such as the pavements and embankment $[2,3]$. So it is important to improve the hydrophilic, physical, and mechanical properties of expansive soil for slope stability of embankment and highway engineering and reducing the cost of investment [9].

In recent decades, geotechnical engineers have made great effort to find different methods to improve expansive soil engineering properties [3]. Chemical stabilization is one of the alternative solutions to overcome the undesirable swell-shrink potentials of the expansive soils, which has been extensively used [10]. When amendment is added into soils, the reaction with clay particles will lead to the improvement in many expansive soil engineering properties [11]. In addition, various methods of chemical modifier have been developed. Among them, inorganic admixture such as lime, fly ash, and cement and organic stabilization like 
TABLE 1: Physical properties of expansive soil.

\begin{tabular}{lccccc}
\hline Dry density & Free swell ratio (\%) & Natural water content (\%) & Liquid limit (\%) & Plastic limit (\%) & Specific gravity \\
\hline 1.53 & 55.0 & 20.2 & 54.0 & 25.0 & 2.74 \\
\hline
\end{tabular}

ISS, HEC, $\mathrm{K}^{+}$, and polyvinyl alcohol are the most widely applied methods for controlling the swell-shrink potentials $[10,12-16]$. On the other hand, new methods are still being developed to increase the strength properties and to reduce the swell potential of expansive soils [4]. With the intensive study of expansion mechanism of expansive soil as well as the continuous exploration of the amendment, a new kind of stabilizer has come to light.

Because of the lowest hydration energy, $\mathrm{K}^{+}$is regarded as the best hydration swelling inhibitors [17]. However, it works with hydrous expansive soil and the effect of the single role is limited [18]. A kind of cationic surfactant named octadecyl trimethyl ammonium chloride (chemical formula $\mathrm{C}_{21} \mathrm{H}_{46} \mathrm{NCl}$ ) or TC-8/OTAC for short is considered. It has a good compatibility with other additives, and the synergistic effect is significant [19]. Therefore, a new stabilizer OTAC$\mathrm{KCl}$ is developed. This new ameliorant can be soluble in water or other solvents. The solution is sprayed on the surface of natural expansive soil slope and diffuses throughout the soil internal by permeation, and then the soil properties can be improved efficiently.

This study aims to clarify the influence of cyclic wetting and drying on the swelling behavior and strength properties of natural expansive soils improved by OTAC-KCl. Thus, an attempt to intermingle OTAC-KCl with expansive soil for physical and mechanical properties studying is presented in this paper.

\section{Materials, Mechanism, Optimum Ameliorant Content, and Curing Period Determination}

As a prerequisite of this research, the engineering properties of the expansive soil used, swelling potential, shear strength, and unconfined compressive strength are determined in the laboratory according to the pertinent tests specified in GB/T 50123-1999 [20].

2.1. Materials. Expansive soil used in this study is from Nanjing. It is a typical clayey soil extensively distributed in Eastern China, which will cause damage to the slope safety. All representative soil samples are subjected to engineering properties measurements, including hydrometer tests, Atterberg limits, and free swell tests. All the results are presented in Table 1.

2.2. Mechanism. Expansive soil used in this study is mainly composed of hydrophilic clay minerals, which are montmorillonite, illite, and so forth. Montmorillonite, which is with a high cation exchange capacity, plays a decisive role in swell-shrink characteristic of expansive soil [21]. It is a kind of layered aluminosilicate minerals, and its unit cell consists of a silicon-oxygen tetrahedron and an aluminumoxygen octahedron. $\mathrm{Si}^{4+}$ in the tetrahedron and $\mathrm{Al}^{3+}$ in the octahedron can be replaced easily by low cation; thus, the equivalent negative charge increases in the crystal structure, and then the surrounding cations are adsorbed to balance the extra negative charge. Meanwhile, oxygen bridge between montmorillonite crystal layers is very weak and cationic and water molecules can easily get into and expand the interlayer. $\mathrm{KCl}$ and OTAC can dissociate amount of $\mathrm{K}^{+}$and $\mathrm{NH}^{4+}$ when reacting with water in soil. $\mathrm{K}^{+}$and $\mathrm{NH}^{4+}$ near to the clay crystal can extrude water molecules and reform stronger links by intercalating into the crystal. The inhibiting effect on the swell-shrink is notable due to the lowest hydration energy of these two positive ions. OTAC is a kind of cationic surfactant and long-chain polymer, which can produce series of physical and chemical reactions to improve expansive soil engineering properties and turn the soil's hydrophilicity into hydrophobicity. The mechanism of OTAC-KCl can be divided into two aspects. Firstly, the hydrophilic radical with positive charge is absorbed on the surface of clay mineral; thus, the hydrophobicity of soil gets strengthened and the reaction of soil and water becomes weakened, and then the swelling ability is suppressed. Secondly, due to the reaction between amendment and soil, firm space grid structures are formed among particles; the expansive soil strength will be improved [22].

2.3. Free Swell Test and the Optimum Proportion of OTAC and $\mathrm{KCl}$. The expansive soil is air-dried and then the calcareous concretions were removed. After these, it is pulverized with a plastic mallet to crush the lumps and sieved at $2 \mathrm{~mm}$. The different dosages of OTAC and $\mathrm{KCl}$ by taking into account mass ratio of the dried soil are prepared. The ameliorants are dissolved in water and sprayed on the expansive soil surface; eventually, they permeate through soil. Three types of mixtures, namely, soil-OTAC, soil-KCl, and soil-OTAC$\mathrm{KCl}$, are prepared. The water contents of natural soil and three types of improved specimens are all controlled with the standard of $20 \%$ or so according to the initial moisture content. All the prepared samples are sealed in plastic bags for $48 \mathrm{~h}$.

Once the amelioration period is achieved, the soil is removed from the sealed container and dried carefully; then it is pulverized until all the particles passed a $0.5 \mathrm{~mm}$ sieve. Free swell test of all the soil samples is conducted to measure the improved effect of different ameliorants and dosage. The effect of different content of amendments on the free swell ratio of clayey soil samples is shown in Table 2.

Table 2 shows that, as $\mathrm{KCl}$ works alone, free swell ratio decreases a little in the case of a high content. As for OTAC, the rate can reduce to the desired value with a high dosage of $1.5 \%$. Big consumption brings a higher cost. Therefore, $\mathrm{KCl}$ and $\mathrm{OTAC}$ combination is more reasonable. Considering 
TABLE 2: Free swell rate of improved soil.

\begin{tabular}{lcc}
\hline \multicolumn{2}{c}{$\begin{array}{c}\text { Modifier types and dosage } \\
\text { OTAC (\%) }\end{array}$} & FCl (\%) \\
\hline- & 6 & 47 \\
1.5 & - & 36 \\
1.0 & - & 41 \\
0.5 & 1 & 40 \\
0.5 & 2 & 33 \\
0.5 & 4 & 31 \\
0.5 & 6 & 30 \\
0.5 & 8 & 27 \\
0.3 & 2 & 34 \\
0.3 & 3 & 31 \\
0.3 & 6 & 25 \\
\hline
\end{tabular}

the improved effect and economy cost, the combination of $0.3 \% \mathrm{OTAC}+3 \% \mathrm{KCl}$ is chosen.

2.4. Unconfined Compressive Strength Test and Optimum Curing Period. Soil specimens are prepared according to the procedure represented in Section 2.3. Improved specimens are prepared by adding $0.3 \%$ OTAC and $3 \% \mathrm{KCl}$ to the clayey soil. After a thorough permeation, both untreated and treated soil specimens are compacted into cylindrical soil samplers with $50 \mathrm{~mm}$ diameter and $50 \mathrm{~mm}$ height. All specimens are prepared at the initial moisture contents $20 \%$ and dry density $1.53 \mathrm{~g} / \mathrm{cm}^{3}$. Then each kind of sample is divided into 3 groups and cured in wet sand curing box for 7 days, 14 days, and 28 days, respectively.

The samples are saturated before tests. Because the vacuum saturation apparatus is inappropriate for UCS specimens' size, process of saturation is simplified. The cured samples are taken from curing box and then soaked in water for $48 \mathrm{~h}$ to saturate fully. Before the UCS test, the side and bottom of the samples are coated with vaseline to prevent moisture evaporation during the experiment. Unconfined compression strengths test is performed on these samples with the strain rate of $0.4 \mathrm{~mm} / \mathrm{min}$ until specimens failed during 7-15 min. When the dynamometer peak is gotten, tests will be ended after axial strain growths 3\% 5\%. Otherwise, the tests will be stopped until axial strain reducing $20 \%$. Every group carries out two sets of tests to ensure the accuracy. The UCS values of untreated and treated samples for different curing times are presented in Table 3 and the UCS curves with axial strain are shown in Figure 1.

No matter maintained or not, all of the untreated samples crack when soaking in water within a few minutes. Uncured improved samples damage a little within one hour and lose strength after two hours. The improved samples maintained 7 days are in good conditions basically; the samples maintained integrity when soaking in water for 48 hours and there are little peelings on the specimens. Treated samples are cured for 14 or 28 days without any peelings or cracks in the process of soaking. From Table 3 and Figure 1, it can be observed that the best curing duration of treated soils is 14 days. Comparing 7 days with 14 days, we conclude that
TABLE 3: Unconfined compressive strength of untreated and treated soil under different curing periods.

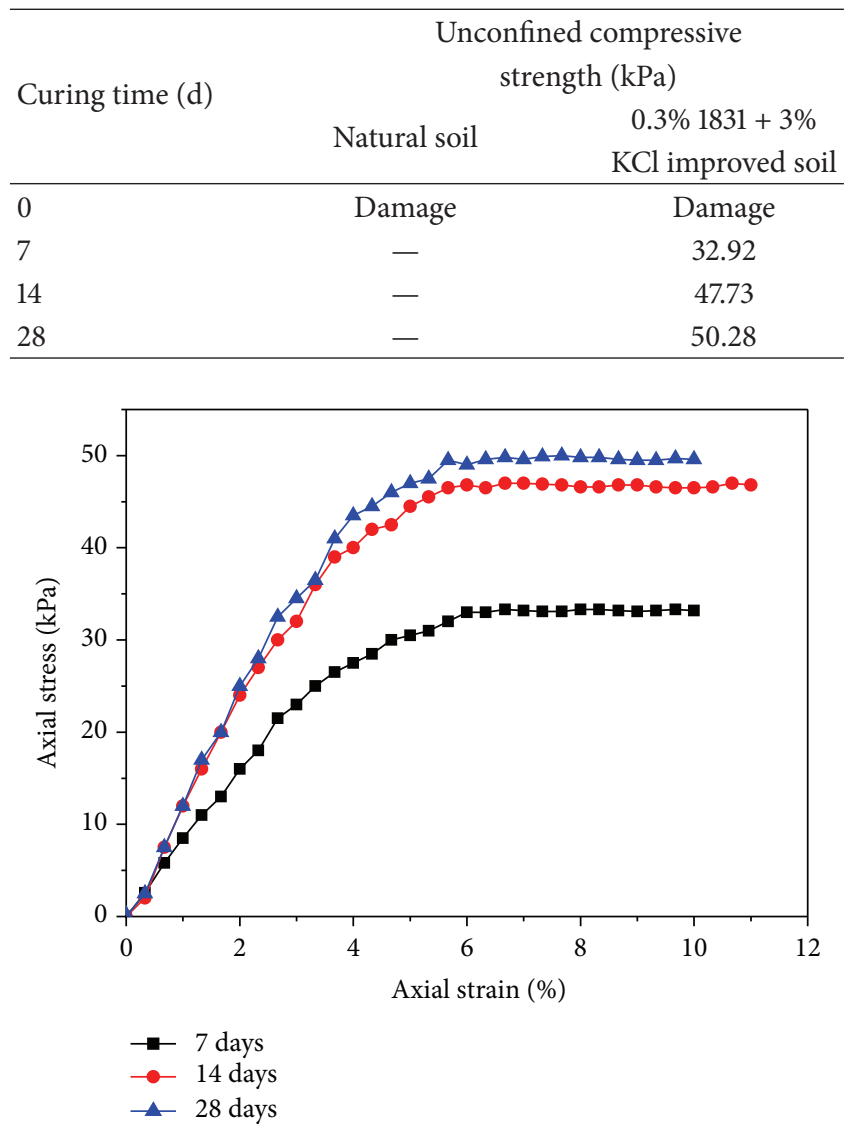

FIGURE 1: Unconfined compressive strength curves of improved soil with axial strain under different curing times.

the unconfined compressive strength increases with the curing period. However, when the soil samples are maintained 28 days, the UC strength does not have any obvious increase. Soil specimens maintain stability after 14-day curing time.

Cyclic wetting-drying experiments are carried out in this research to measure the physical and mechanical properties of the expansive soil improved by $0.3 \%$ STAC $+3 \% \mathrm{KCl}$ combinations after 14-day curing time.

\section{Testing Program and Results}

The wetting-drying cycle test has the greatest advantage of being repeatable on the same samples [4, 23-25]. Water stability of stabilized soil under wetting-drying cycles is investigated by two approaches. The first one takes the swelling stability into account, and the other one measures the loss of shear strength and unconfined compression strength [26].

3.1. Cyclic Swelling Potential Test. Soil specimens are prepared following the procedure described in Section 2.3. Improved specimens are prepared by mixing the clayey soil with $0.3 \%$ OTAC and $3 \% \mathrm{KCl}$. Soil specimens with a diameter of 


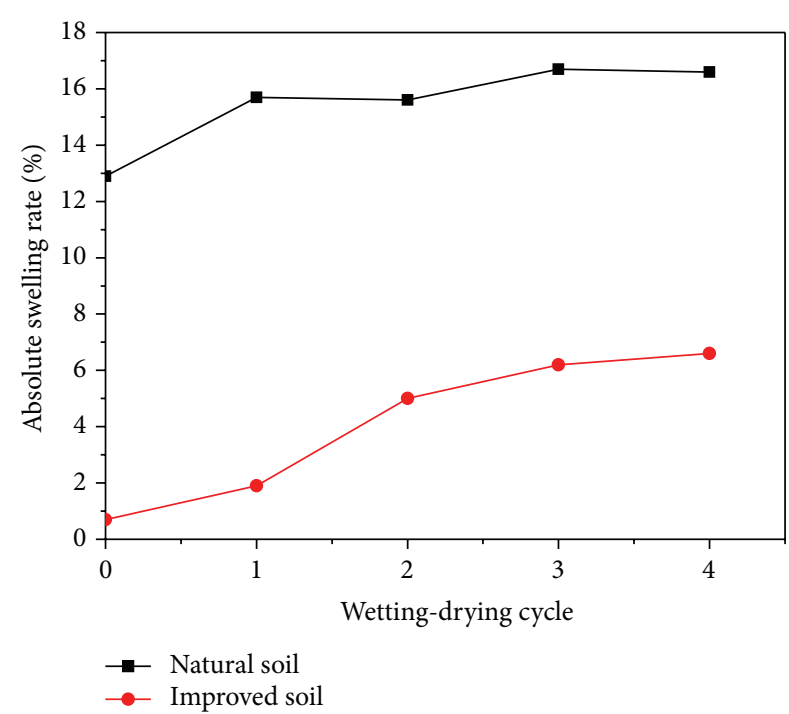

FIGURE 2: Absolute swelling ratio trends of the natural soil and improved soil.

$61.8 \mathrm{~mm}$ and height of $20 \mathrm{~mm}$ are made by cylindrical thinwall samplers. The samples are cured in wet sand curing box for 14 days. After the curing process, all samples are subjected to 4 cycles of wetting-drying. A wetting-drying cycle consists of submerging in water until saturation and airdrying to the initial moisture content of $20 \%$ (by the weight of the samples). The cured cutting-ring specimens are saturated with a vacuum saturation apparatus. Specimens are put in the apparatus and soaked in water for 48 hours. This phase is defined as the 0 th cycle. Then, the wetted samples are taken out and air-dried to the initial moisture content about $20 \%$. So far, a complete cycle is finished.

Initial height of the specimens at the beginning of swellshrink cycle marked $h_{0}$ is then manually measured by vernier caliper. Then, the heights of saturated specimens named $h_{w 1}$ and air-dried samples named $h_{1}$ are all measured. According to Liu et al. [27] and Wu et al. [28], the absolute swelling ratio and relative ratio are defined to quantitative analysis the regularity and reversibility of swell-shrink characteristics during cyclic wetting-drying process.

Definition of the absolute swelling ratio is the following: $\delta_{a}: \delta_{a}=\left(\left(h_{w}-h_{0}\right) / h_{0}\right) \times 100 \%$, where $h_{0}$ is the initial height and $h_{w}$ is the height after expansion.

Definition of the relative swelling ratio is the following: $\delta_{r}: \delta_{r}=\left(\left(h_{w}-h_{i}\right) / h_{i}\right) \times 100 \%$, where $h_{w}$ is the height after expansion and $h_{i}$ is the height before certain wet-dry cycle.

The tests are carried on until the end of four cycles, and the results are given in Figures 2 and 3 after 4 wetting and drying cycles.

From Figures 2 and 3, it can be concluded that the absolute swelling ratio of modified soil is always smaller than natural soil and the suppression of swelling in stabilized specimens is obvious. The absolute swelling ratio reaches equilibrium at the 4 th cycle of wetting-drying and increases with increasing wetting and drying cycles for both kinds of soil samples. The values are $16.5 \%$ and $6.54 \%$, respectively,

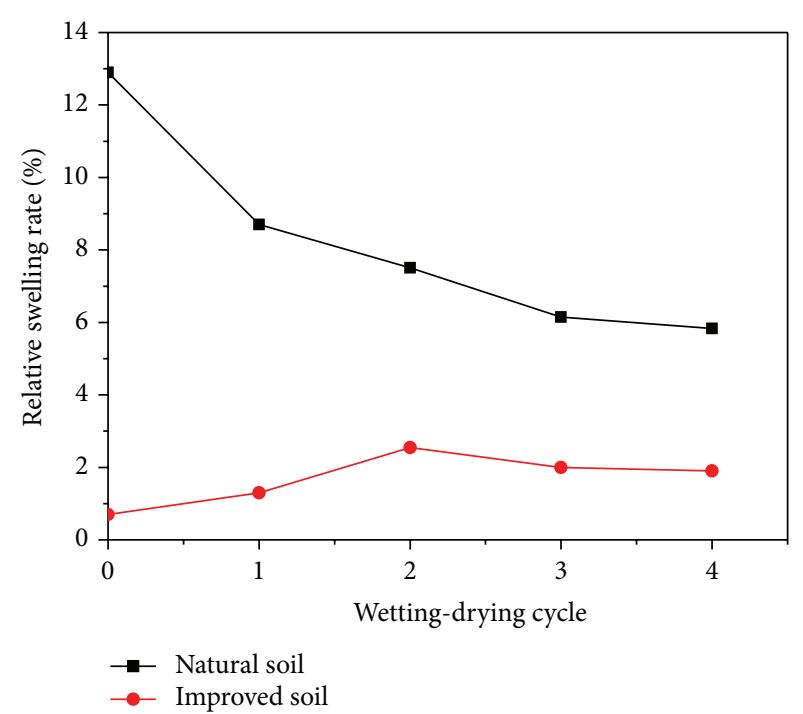

FIGURE 3: Relative swelling ratio trends of the natural soil and improved soil.

after 4 cycles, while the initial values are $12.9 \%$ and $0.59 \%$. As for relative swelling ratio, natural soil decreases with increasing cyclic wetting and drying, while improved soil increases during the first two cycles, a peak occurs in the second loop, and then relative swelling ratio reduces to be stable gradually. This result shows that the expansion of the soil is not entirely reversible.

According to the results of experiment, soil stabilized with $0.3 \%$ OTAC and $3 \% \mathrm{KCl}$ has a quite low swelling ratio even wetting-drying for 4 times. The effect of ameliorants on the swelling ability during wetting-drying cycles is notable compared with natural soil.

3.2. Cyclic Direct Shear Test. Natural and improved soil samples are made by cutting ring molds and cured for 14 days in wet sand curing box. Each kind of soil sample is divided into four groups and saturated with a vacuum saturation apparatus. This is called the 0th cycles. The first wettingdrying cycle is completed after air-drying the saturated samples to initial moisture content about $20 \%$. Direct shear tests are carried out by quadruple strain controlled direct shear apparatus (Nanjing Soil Instrument Factory Co. Ltd.), soil samples are placed in a shear testing device, and normal loads of 50,100,150, and $200 \mathrm{kPa}$ are applied and sheared immediately. In these tests, the natural and stabilized soil specimens are subjected to 4 cycles of alternate wettingdrying. In order to get the trend of strength change during cycles, the samples are tested at the 0th cycles and the 2nd and 4 th cycles. Results are described in Figures 4 and 5 and Table 4.

The figures indicate that the shear strength of soil modified with $0.3 \% \mathrm{OTAC}+3 \% \mathrm{KCl}$ is improved significantly. Shear strength reduces with increasing wetting-drying cycles while it increases with vertical pressure for both soils. The shear strength of a soil can be expressed by two parameters as the cohesion $(c)$ and the internal friction angle $(\varphi)$. 
TABLE 4: The results of shear strength parameters during cyclic wetting-drying process.

\begin{tabular}{|c|c|c|c|c|c|c|c|}
\hline \multirow{2}{*}{ Types of soil } & \multicolumn{4}{|c|}{ Shear strength under different vertical pressures $(\mathrm{kPa})$} & \multirow{2}{*}{$\begin{array}{l}\text { Internal friction angle } \\
\varphi /^{\circ}\end{array}$} & \multirow{2}{*}{$\begin{array}{c}\text { Cohesion } \\
c / \mathrm{kPa}\end{array}$} & \multirow{2}{*}{ Note } \\
\hline & 50 & 100 & 150 & 200 & & & \\
\hline \multicolumn{8}{|l|}{ Natural soil } \\
\hline 0th cycle & 19.1 & 29.6 & 37.6 & 40.7 & 8.3 & 13.5 & \multirow{7}{*}{ Saturated samples } \\
\hline 2nd cycle & 15.8 & 24.3 & 32.1 & 36.1 & 7.8 & 9.9 & \\
\hline 4th cycle & 11.6 & 16.5 & 25.7 & 30.7 & 7.6 & 4.5 & \\
\hline Improved soil & & & & & & & \\
\hline 0th cycle & 41.9 & 50.3 & 58.6 & 74.4 & 12.0 & 29.8 & \\
\hline 2nd cycle & 36.9 & 43.6 & 49.8 & 65.3 & 10.4 & 26.0 & \\
\hline 4th cycle & 30.4 & 36.4 & 43.2 & 56.1 & 9.5 & 20.6 & \\
\hline
\end{tabular}

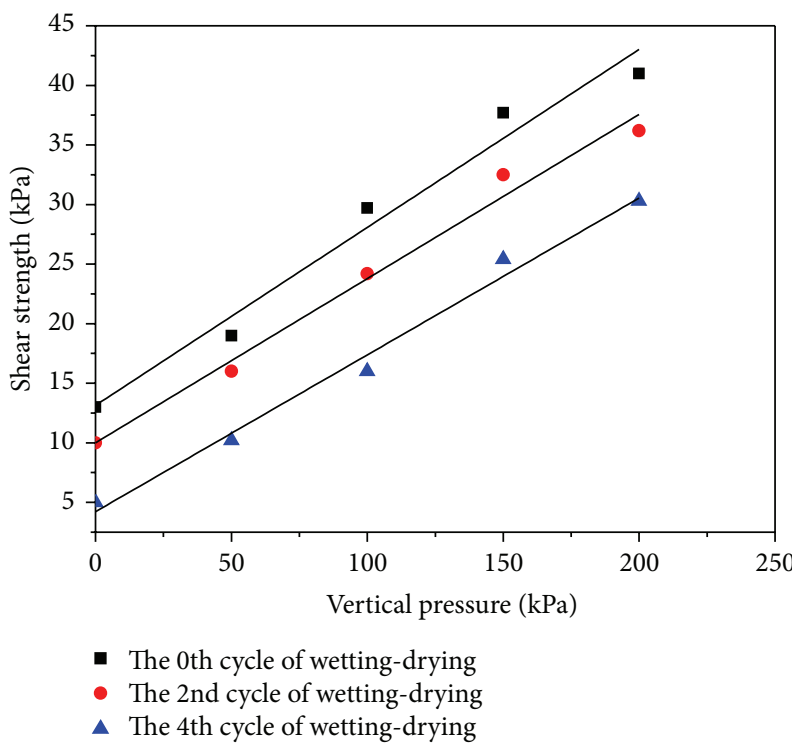

FIGURE 4: Shear strength of natural soil during wetting-drying cycles.

Mean $c$ and $\varphi$ of the studied expansive soil and stabilized soil are presented in Table 4, respectively. Cohesions are all diminished with the cycles while internal friction strengths changed a little. Comparing with the natural soil, the $0.3 \%$ OTAC $+3 \% \mathrm{KCl}$ amended soil has significantly higher $c$ values. Expansive soil improved by STAC combined with $\mathrm{KCl}$ shows good water stability based on shear strength.

3.3. Cyclic Unconfined Compressive Strength Test. Multiple modified specimens are prepared at optimum OTAC-KCl dosages and the initial moisture contents. Samples are cured in wet sand curing box for 14 days and immersed in water for $48 \mathrm{~h}$. The influence of additive on the strength behavior of treated soils is examined by performing UCS studies on the same soils at the 0th cycles, 2nd cycle, and 4th cycle. In comparison, untreated soils are also tested at the same cycles. The procedure is the same as mentioned in Section 2.4. The cylindrical samples taken out from UCS apparatus and airdried to initial water content are used for the next wetting and drying cycle. The wetting-drying procedure is terminated

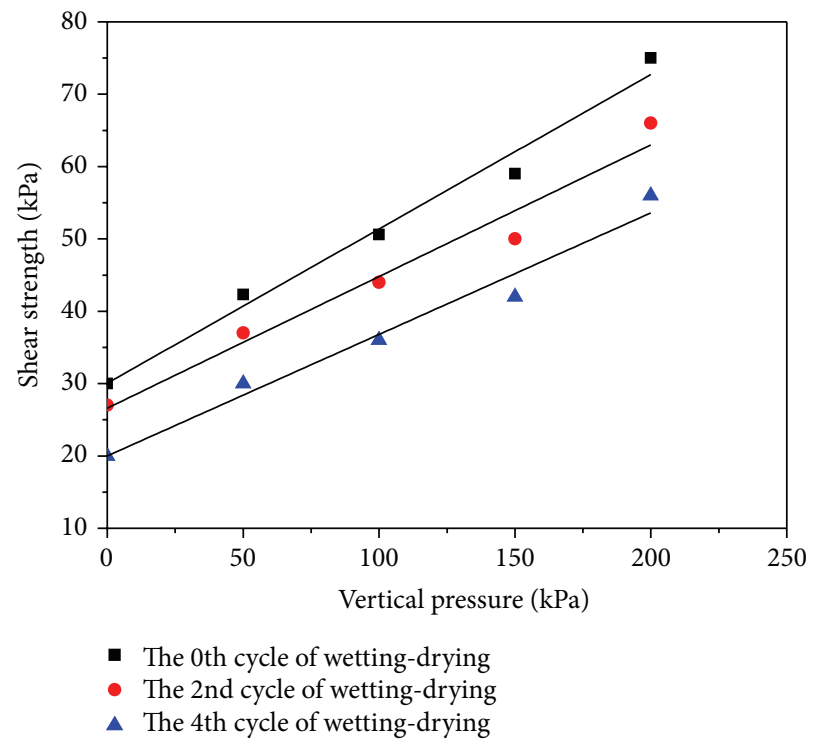

FIGURE 5: Shear strength of improved soil during wetting-drying cycles.

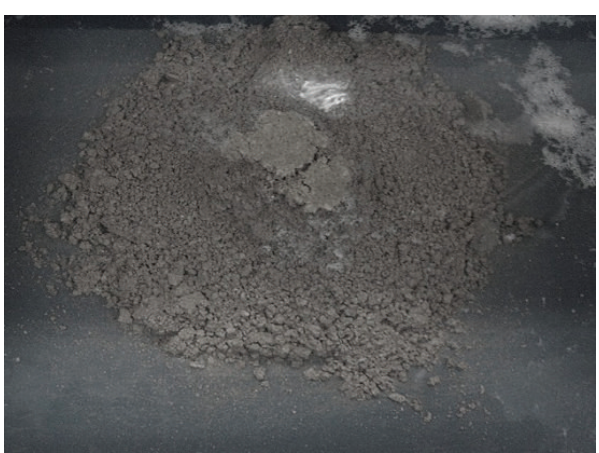

FIGURE 6: Natural samples disintegrate after 48-hour immersion in water.

after 4 cycles of wetting-drying. The UCS values of untreated and treated samples for different wet-dry cycle times are presented in Table 5 and the photos taken in the process of experiments are shown in Figures 6, 7, 8, and 9. 
TABLE 5: Results of unconfined compressive strength during cyclic wetting-drying process.

\begin{tabular}{lcccl}
\hline Types of soil & Cycles & $\begin{array}{c}\text { Unconfined compressive } \\
\text { strength }(\mathrm{kPa})\end{array}$ & Strength loss $(\%)$ & Conditions of samples immersed in water \\
\hline Natural soil & 0th cycles & - & - & Cracking after 10-minute immersion in water \\
\hline Improved soil & 2nd cycle & 47.73 & 13.6 & $\begin{array}{l}\text { Keeping good conditions without peelings } \\
\text { In good conditions basically, with a little amount } \\
\text { of peelings on the edges } \\
\text { In good conditions overall, with a little amount } \\
\text { of cracks on the surface and peelings on the } \\
\text { edges }\end{array}$ \\
\hline
\end{tabular}

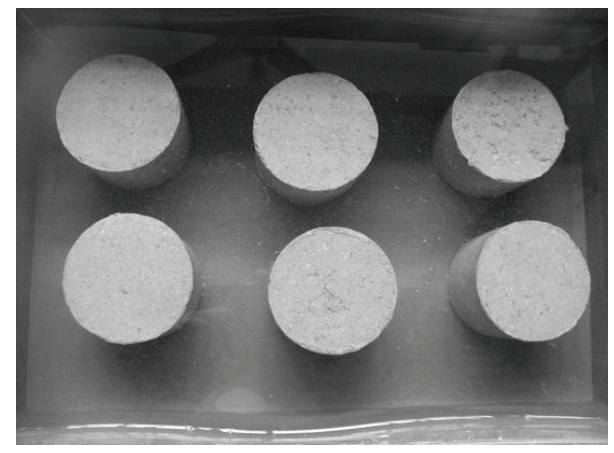

FIGURE 7: Improved samples immersed in water for $48 \mathrm{~h}$ at 0 wetting-drying cycles.

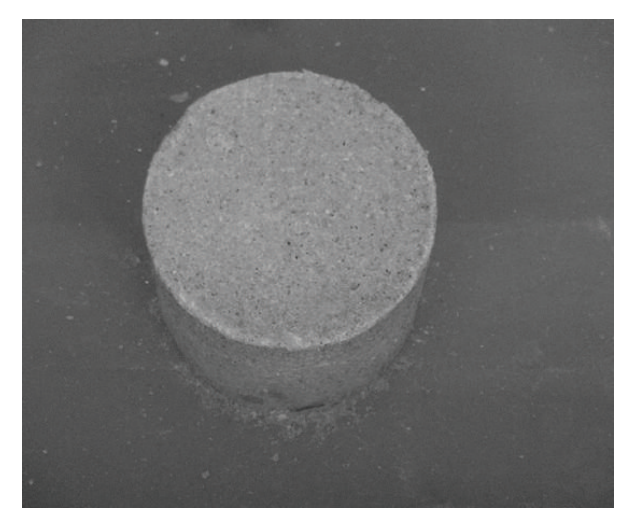

FIGURE 8: Improved samples immersed in water for $48 \mathrm{~h}$ at $2 \mathrm{nd}$ cycle of wetting-drying.

As shown in Table 5, the results obtained from UCS tests indicate that, for the particular proportions of OTAC and $\mathrm{KCl}$ in soil, an increase in wet-dry cycles induces a gradual weakness in strength, and the strength loss is $21.8 \%$. The UCS values of improved soil samples increase a lot comparing with the natural soil samples and the gain of durability is noticeable.

Figures 6 to 9 show that water stabilities of untreated specimens are quite poor and they collapse after immersing in water for the first 48 hours. Because the untreated samples disintegrate after being immersed in water, all the untreated samples fail in the water stability test. However, soil samples

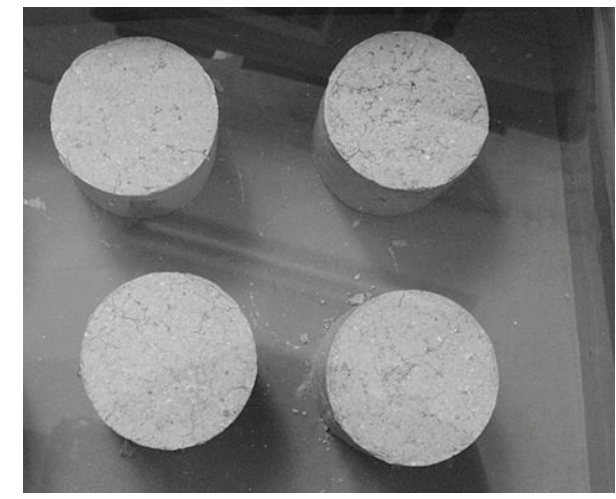

FIGURE 9: Improved samples immersed in water for $48 \mathrm{~h}$ at 4 th cycle of wetting-drying.

improved by OTAC- $\mathrm{KCl}$ can go through numerous wettingdrying cycles. Due to the admixtures, samples keep a good condition until the end of the test.

\section{Conclusions}

Based on the study, the effect on the swelling potential, shear strength, and unconfined compressive strength behavior of expansive soils improved with $0.3 \%$ OTAC - 3\% KCl during wetting-drying cycles has been investigated and the main conclusions are as follows.

Comparing with the natural expansive soil samples, it is found that the improved soil samples will have a lower swelling ability and a higher strength. The absolute swelling ratio increases with the increasing wetting-drying cycles while the relative swelling rates decrease with the cycles, and both of them reach the final equilibrium at the last cycle for the natural and modified soil samples. By the application of the wetting-drying cycles on both untreated and treated soils, the shear strength will reduce. Expansive soil improved by OTAC- $\mathrm{KCl}$ has significantly higher $c$ values; stabilized soil shows enough water stability based on shear strength. Untreated specimens have poor water stability, which will collapse after immersion in water at the first cycle. However, for the modified soil, an increase in wetting-drying cycle will induce a gradual weakness in strength; the strength loss is $21.8 \%$ after 4 cycles. Soil samples improved by OTAC-KCl 
can bear numerous wetting-drying cycles and keep a good condition until the end of the test.

\section{Conflict of Interests}

The authors declare that there is no conflict of interests regarding the publication of this paper.

\section{Acknowledgments}

This research is supported by the Fundamental Research Funds for the Central Universities (no. 2013B34914), which is greatly appreciated. The laboratory portion of this research was carried out in Key Laboratory of Ministry of Education for Geotechnics and Embankment Engineering of Hohai University. The authors also like to acknowledge the authorities of the Civil Engineering Department.

\section{References}

[1] C. Gallage, M. Cochrane, and J. Ramanujam, "Effects of lime content and amelioration period in double lime application on the strength of lime treated expansive sub-grade soils," in Proceedings of the 2nd International Conference on Transportation Geotechnics (ICTG '12), pp. 99-104, September 2012.

[2] S. B. Ikizler, M. Vekli, E. Dogan, M. Aytekin, and F. Kocabas, "Prediction of swelling pressures of expansive soils using soft computing methods," Neural Computing and Applications, vol. 24, no. 2, pp. 473-485, 2014.

[3] F. Yazdandoust and S. S. Yasrobi, "Effect of cyclic wetting and drying on swelling behavior of polymer-stabilized expansive clays," Applied Clay Science, vol. 50, no. 4, pp. 461-468, 2010.

[4] E. Kalkan, "Impact of wetting-drying cycles on swelling behavior of clayey soils modified by silica fume," Applied Clay Science, vol. 52, no. 4, pp. 345-352, 2011.

[5] W. G. Ring, "Shrink-Swell potential of soils," Highways Research Record 119, National Academy of Science-National Research Council Publication no. 1360, Washington, DC, USA, 1966.

[6] M. Popescu, "Behavior of expansive soils with crumb structure," in Proceedings of the 4th International Conference on Expansive Soils, vol. 1, pp. 158-171, ASCE, New York, NY, USA, 1980.

[7] V. I. Osipov, N. N. Bik, and N. A. Rumjantseva, "Cyclic swelling of clays," Applied Clay Science, vol. 2, no. 4, pp. 363-374, 1987.

[8] A. A. Basma, A. S. Al-Homoud, A. I. H. Malkawi, and M. A. AlBashabsheh, "Swelling-shrinkage behavior of natural expansive clays," Applied Clay Science, vol. 11, no. 2-4, pp. 211-227, 1996.

[9] Z. J. Wang and J. B. Liang, "Engineering characteristics of expansive soil and its improved research development," Advanced Materials Research, vol. 884-885, pp. 657-661, 2014.

[10] T. Thyagaraj, S. M. Rao, P. Sai Suresh, and U. Salini, "Laboratory studies on stabilization of an expansive soil by lime precipitation technique," Journal of Materials in Civil Engineering, vol. 24, no. 8, pp. 1067-1075, 2012.

[11] Y. Cai, B. Shi, C. W. W. Ng, and C. S. Tang, "Effect of polypropylene fibre and lime admixture on engineering properties of clayey soil," Engineering Geology, vol. 87, no. 3-4, pp. 230-240, 2006.

[12] J.-Q. Yu, R.-L. Hu, H.-M. Shang, F.-P. Cui, and M.-L. Yang, "Synergistic reaction of $\mathrm{K}+$ and polyvinyl alcohol on restraing swelling and hydrating behavior of expansive soil," Chinese
Journal of Geotechnical Engineering, vol. 30, no. 6, pp. 900-905, 2008 (Chinese).

[13] L.-J. He and X.-Y. Tang, "Laboratory studies on expansive soil improved by HEC," Yellow River, vol. 32, no. 9, pp. 148-151, 2010 (Chinese).

[14] Q. B. Liu, W. Xiang, and D. S. Cui, "Effect of ionic soil stabilizer on bound water of expansive soils," Chinese Journal of Geotechnical Engineering, vol. 34, no. 10, pp. 1887-1895, 2012 (Chinese).

[15] S. Saride, A. J. Puppala, and S. R. Chikyala, "Swell-shrink and strength behaviors of lime and cement stabilized expansive organic clays," Applied Clay Science, vol. 85, no. 1, pp. 39-45, 2013.

[16] P. Voottipruex and P. Jamsawang, "Characteristics of expansive soils improved with cement and fly ash in Northern Thailand," Geomechanics and Engineering, vol. 6, no. 5, pp. 437-453, 2014.

[17] C. Huang, S.-Y. Liu, C.-G. Zhang, X.-G. Mo, and D.-J. Sun, "Inhibition behavior of $\mathrm{NH}_{4}^{+}$, urea and polyethylene glycol on swelling of montmorillonite," Acta Chimica Sinica, vol. 61, no. 7, pp. 983-988, 2003 (Chinese).

[18] B.-T. Wang and F.-H. Zhang, Improvement Technology and Engineering Application of Expansive Soil, Science Press, Beijing, China, 2008 (Chinese).

[19] J. Qiu, F.-F. Yang, J.-J. Li, and X.-J. Lu, "Study on the conditions of preparing organic montmorillonite under the synergic effect of tetraethyl ammonium bromide and octadecylt rimethyl ammonium chloride," Industrial Minerals Processing, vol. 7, pp. 12-15, 2006 (Chinese).

[20] Ministry of Construction P.R. China, "Standard for soil test method," Tech. Rep. GB/T 50123-1999, Ministry of Construction P.R. China, Beijing, China, 1999, (Chinese).

[21] J. M. Montenegro, M. Celemín-Matachana, J. Cañizal, and J. Setién, "Ladle furnace slag in the construction of embankments: expansive behavior," Journal of Materials in Civil Engineering, vol. 25, no. 8, pp. 972-979, 2013.

[22] X.-L. Qiu and B.-T. Wang, "Experimental research on chemical modification of expansive soil and its application in slope engineering," Journal of Water Resources and Architectural Engineering, vol. 11, no. 2, pp. 190-195, 2013 (Chinese).

[23] A. S. Al-Homoud, A. A. Basma, A. I. H. Malkawi, and M. A. Al Bashabsheh, "Cyclic swelling behavior of clays," Journal of Geotechnical Engineering, vol. 121, no. 7, pp. 562-565, 1995.

[24] Y. Guney, D. Sari, M. Cetin, and M. Tuncan, "Impact of cyclic wetting-drying on swelling behavior of lime-stabilized soil," Handbook of Environmental Chemistry, vol. 42, no. 2, pp. 681688, 2007.

[25] K. S. Subba Rao, S. M. Rao, and S. Gangadhara, "Swelling behavior of a desiccated clay," Geotechnical Testing Journal, vol. 23, no. 2, pp. 193-198, 2000.

[26] U. Calik and E. Sadoglu, "Classification, shear strength, and durability of expansive clayey soil stabilized with lime and perlite," Natural Hazards, vol. 71, no. 3, pp. 1289-1303, 2014.

[27] S. Liu, P. Ji, and L. Fang, "Approach to cyclic swelling behavior of compacted expansive clays," Chinese Journal of Geotechnical Engineering, vol. 21, no. 1, pp. 9-13, 1999 (Chinese).

[28] J. Wu, J. Yuan, S. Yang, and T. Lu, "Experimental study on swellshrinking performance of expansive soil under wetting-drying cycles," Advances in Science and Technology of Water Resources, vol. 33, no. 1, pp. 62-73, 2013 (Chinese). 

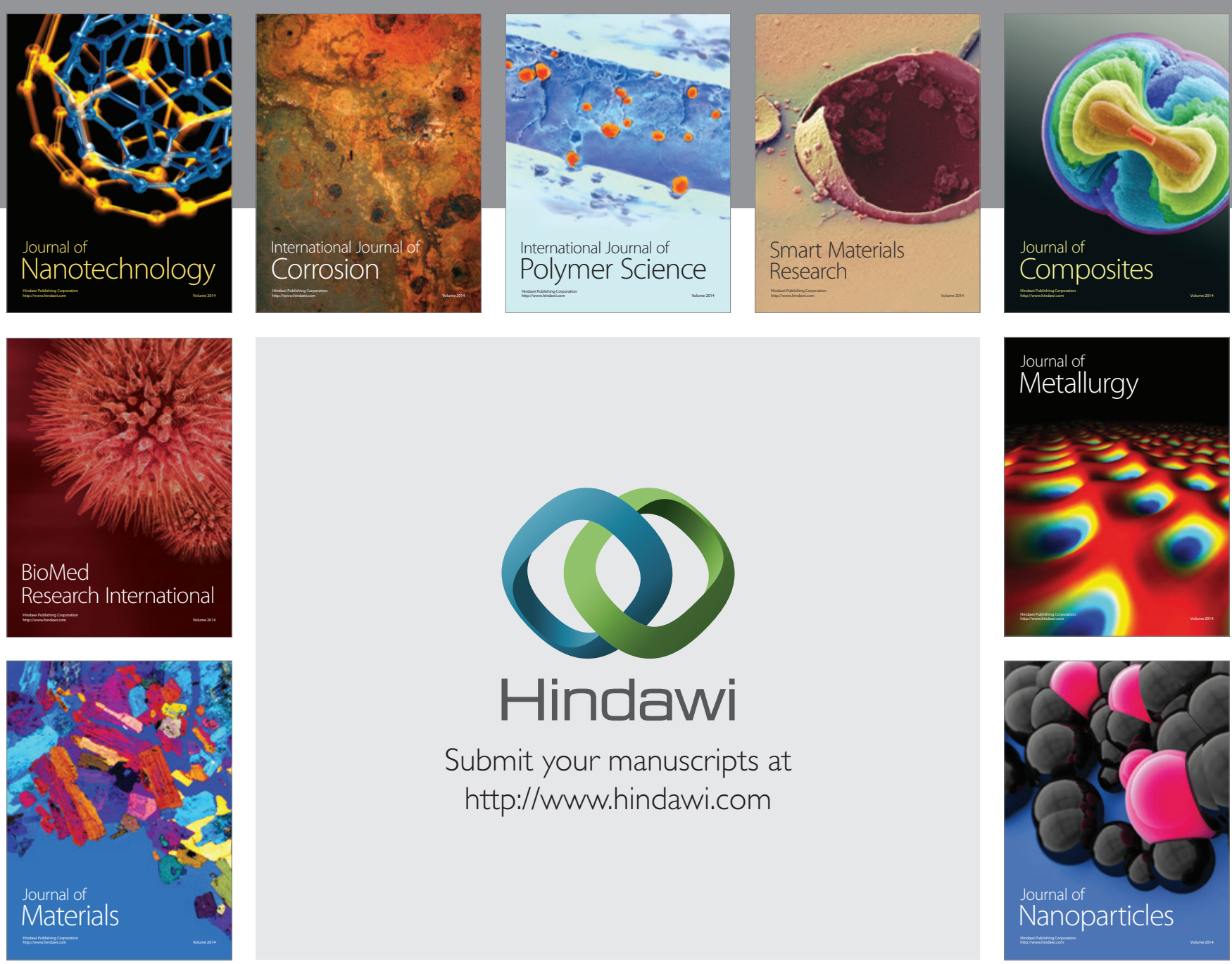

Submit your manuscripts at http://www.hindawi.com
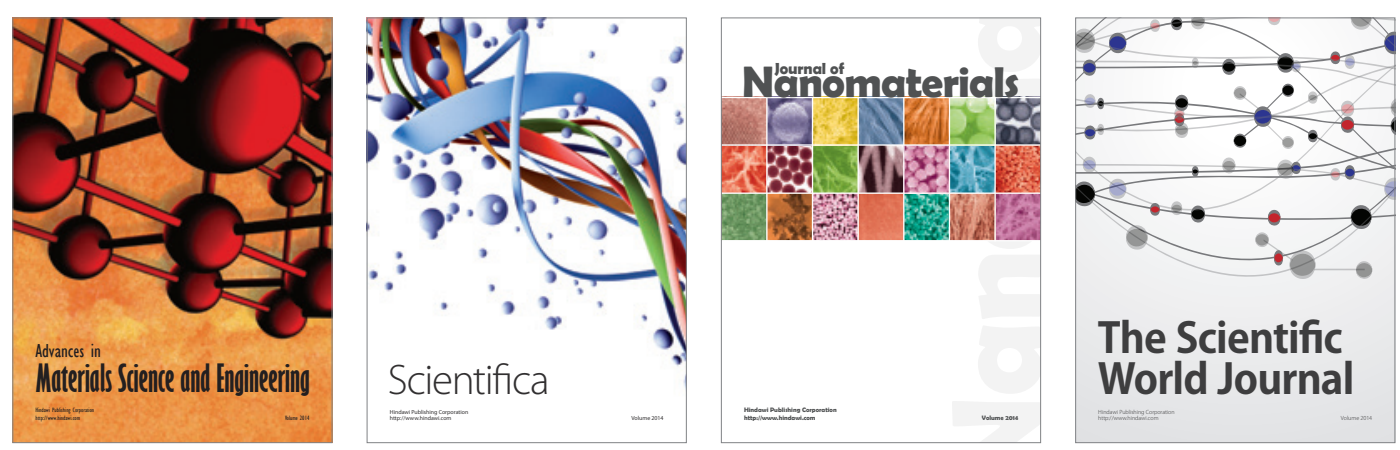

\section{The Scientific World Journal}
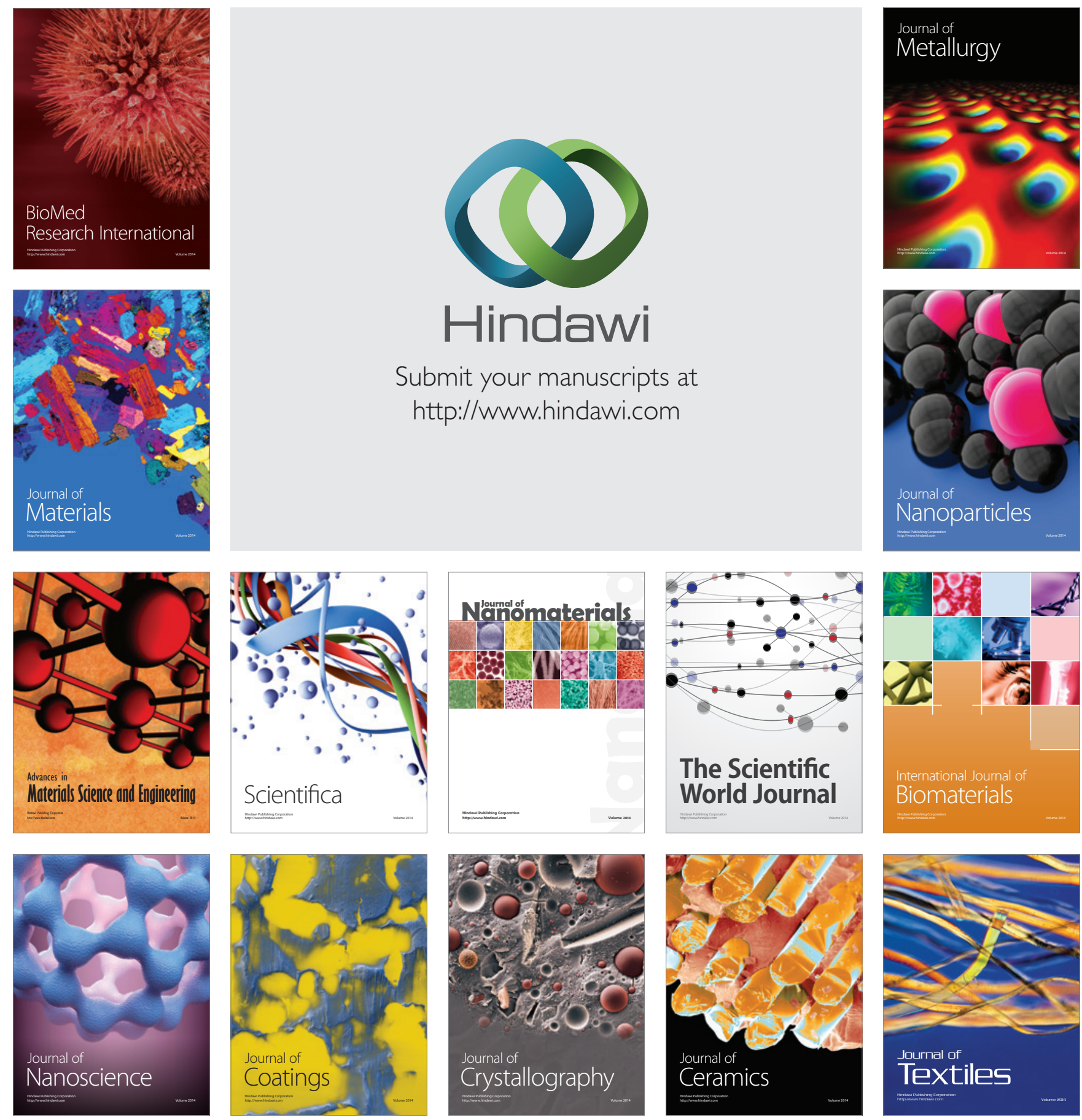